\title{
Numerical Dynamic Simulation of a Train Set Running on Ballasted Track after Derailment
}

\author{
Masahito KUZUTA \\ Researcher, \\ Vehicle Mechanics Laboratory, Railway Dynamics Division \\ Kenji UEKI \\ Manager, \\ Design \& Manufacture, Research \& Development Promotion Division
}

\section{Takefumi MIYAMOTO}

Laboratory Head,

Vehicle Mechanics Laboratory, Railway Dynamics Division

\section{Yukio NISHIYAMA}

Manager,

Design \& Manufacture, Research \& Development Promotion Division

\section{Eiichi MAEBASHI}

Senior Researcher,

Vehicle Mechanics Laboratory, Railway Dynamics Division

\begin{abstract}
The dynamic motion of a train set will be affected by the change in running resistance as the wheels run over sleepers or ballast. It is therefore important to determine the motion of vehicles in such situations both experimentally and theoretically. A 1 to 10 scale model vehicle was used to perform running tests during which the vehicle was made to collide against model iron sleepers. Further running tests were carried out involving a real single bogie falling onto ballast or a concrete sleeper. These experiments were used as a basis to develop a numerical simulation program, capable of calculating the dynamic motion of a train after its derailment, and computed dynamic behavior of 5 cars after their derailment.
\end{abstract}

Keywords: vehicle dynamics simulation, model vehicle, train set buckling, ballasted track, brake force

\section{Introduction}

Following the first ever derailment of a Shinkansen train during the Mid Niigata Prefecture Earthquake in 2004, technical developments have been actively sought to reduce damage to railway vehicles in case of derailment. When a train derails on ballasted track, the vehicles in the train will run on sleepers. So it is important to comprehend the motion of vehicles in such situations both theoretically and experimentally; however it is hard to conduct experiments to reproduce a derailment of a high-speed train using full-scale vehicles. The authors therefore made a 1 to 10 scale model vehicle and carried out running tests where the vehicle was made to collide with model iron sleepers. Running tests were also conducted with a real single bogie falling onto ballast or a concrete sleeper. A numerical simulation program was subsequently developed capable of calculating the dynamic motion of the train after its derailment. This report presents the contents and results of the above experiments and discusses the results of the dynamic behavior of the 5 cars obtained using the above mentioned developed numerical simulation program.
2. Running tests with the $1 / 10$ scale model vehicle and numerical simulation using the two-dimensional model

\subsection{1/10 scale model vehicle}

Figure 1 shows the 1/10 scale model of a normal Shinkansen train vehicle used for the running tests. Its main specifications appear in Table 1 . The spring and damper system of the model vehicle was configured to meet the

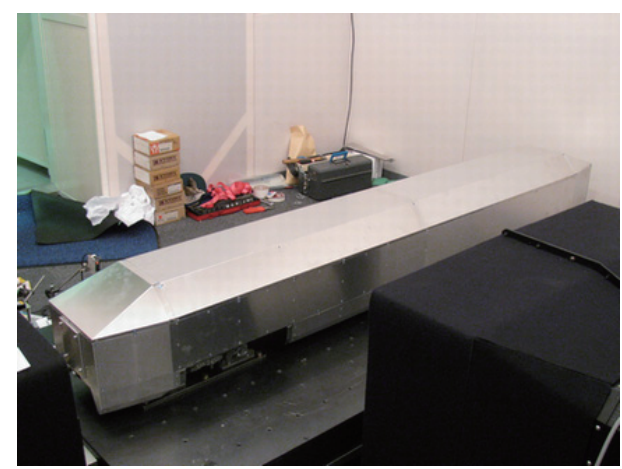

Fig. 1 1/10 scale model vehicle 
Table 1 Principal specification of $1 / 10$ scale model vehicle

\begin{tabular}{l|l}
\hline Scale & $1 / 10$ \\
\hline Weight & about $50 \mathrm{~kg}$ \\
\hline Length & $2.45 \mathrm{~m}$ \\
\hline Width & $0.34 \mathrm{~m}$ \\
\hline $\begin{array}{l}\text { Bogie-center } \\
\text { distance }\end{array}$ & $1.75 \mathrm{~m}$ \\
\hline Wheelbase & $0.25 \mathrm{~m}$ \\
\hline Wheel diameter & $0.086 \mathrm{~m}$ \\
\hline Gauge & $0.1435 \mathrm{~m}$ \\
\hline &
\end{tabular}

scaling law as much as possible, so that acceleration of the model vehicle coincided with that of the real vehicle.

\subsection{Model vehicle running test procedures}

The model vehicle train was positioned, as shown in Fig. 2 on the test apparatus. It was fixed to the pulling truck. The pulling truck and the vehicle were then accelerated as united single body through the accelerating area by rapid contraction of the rubber tube. Only the pulling truck was braked and stopped at the end of the accelerating area while the vehicle was allowed to coast into the test area. Model iron sleepers were positioned in the test area and the vehicle ran jumping and decelerating onto the sleepers. The vehicle finally entered the braking area and stopped. Two types of model iron sleeper were employed: a narrow sleeper (Fig. 3(a)) and wide sleeper (Fig. 3(b)) to determine the influence of the falling margin of a wheel between sleepers. The sleepers were set every $0.0555 \mathrm{~m}$. Varying the speed of the model vehicle by changing the number of rubber tubes, the running speed of the vehicle was measured at the entrance and at the end of the test area.

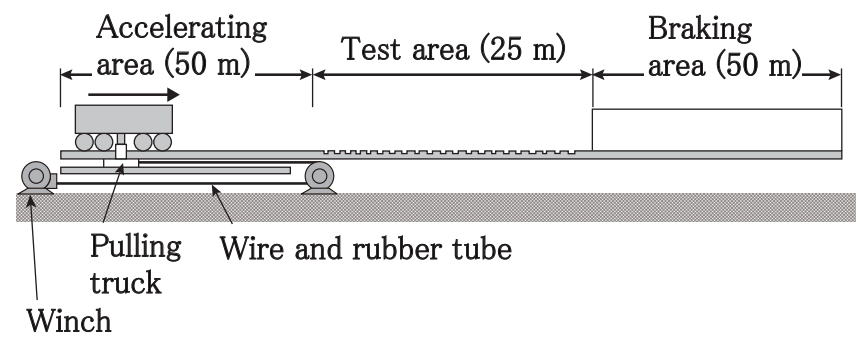

Fig. 2 Test run apparatus

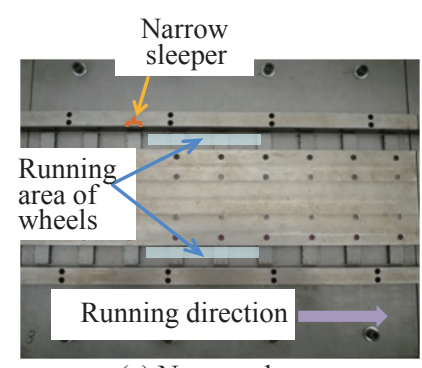

(a) Narrow sleeper

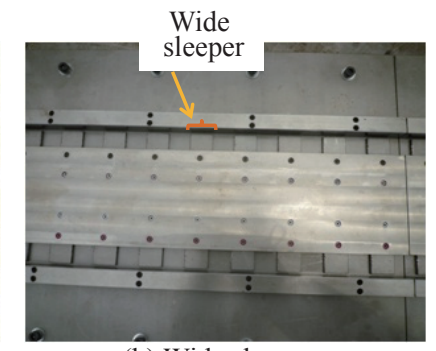

(b) Wide sleeper
Fig. 3 Model iron sleepers

\subsection{Result of running test and numerical simulation using two-dimensional model}

First the equivalent running resistance $(\mu)$ was defined as follows.

$$
\mu=\frac{v_{1}^{2}-v_{2}^{2}}{2 g s}
$$

where $v_{1}$ is the speed of the vehicle at the first speed meter around the entrance of test area $[\mathrm{m} / \mathrm{s}]$;

$v_{2}$ : Speed of the vehicle at the second speed meter around

the end of test area $[\mathrm{m} / \mathrm{s}]$

$g$ : Acceleration of gravity $\left[\mathrm{m} / \mathrm{s}^{2}\right]$;

$s$ : Running distance of the vehicle.

$s$ is $22.5 \mathrm{~m}$ (distance between two speedometers) if the vehicle passes the test area completely. When $v_{1}$ is small, the vehicle might stop in the test area; then $v_{2}$ is 0 and $s$ is

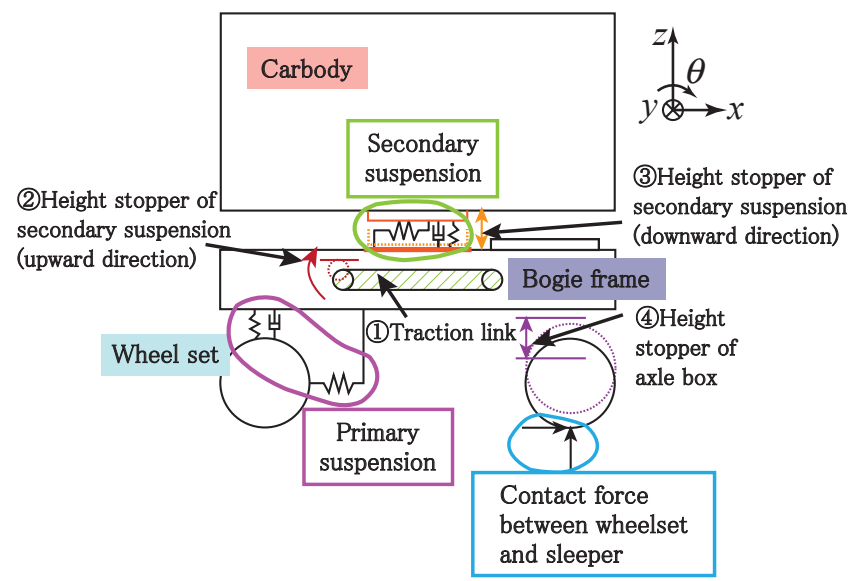

Fig. 4 Two-dementional half-car section model

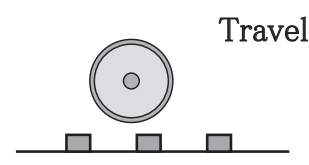

(a) Contactless

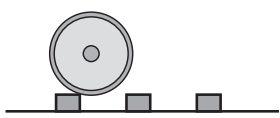

(c) Contact to leading edge

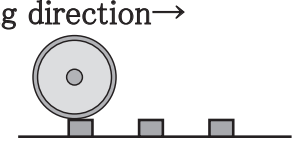

(b) Contact onto top surface

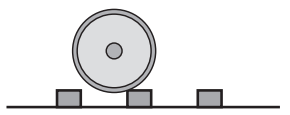

(d) Contact to trailing edge
Fig. 5 Geometrical contact situation between wheelset and sleeper

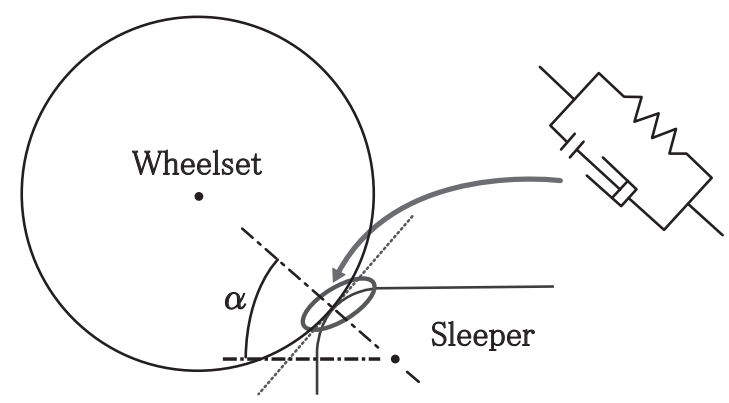

Fig. 6 Mechanical modeling of contact between wheelset and sleeper 


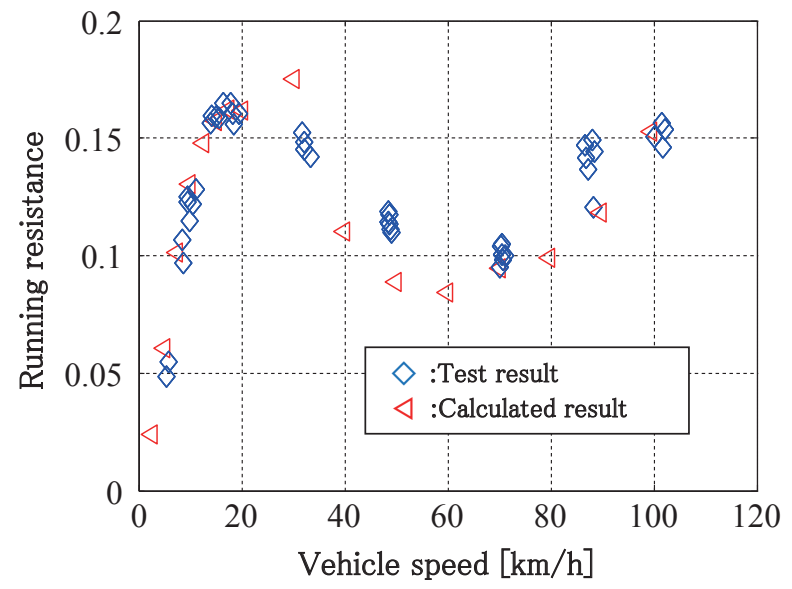

(a) Narrow sleeper

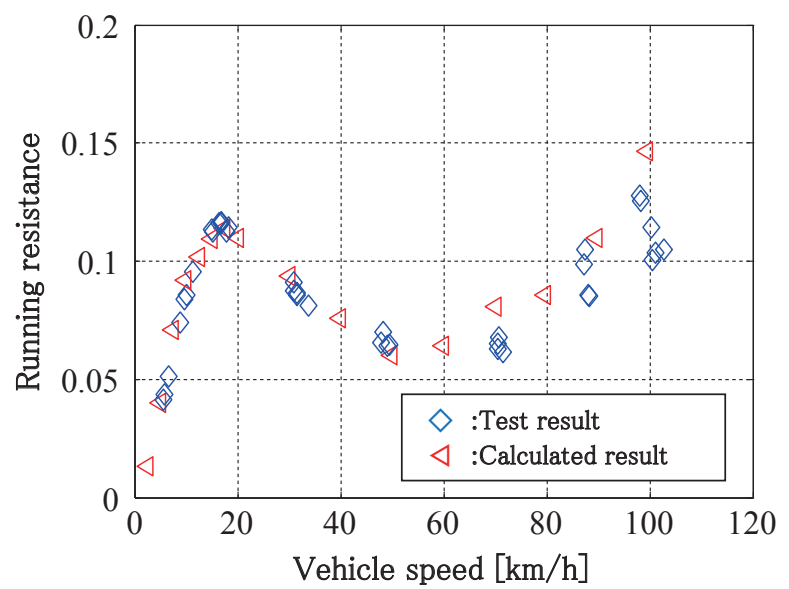

(b) Wide sleeper

Fig. 7 Equivalent running resistance of $1 / 10$ scale vehicle (test results and calculation results using single car model)

defined as the distance from the entrance of the test area to the position of the first wheelset of the stopping train. Running test results were then collated and the equivalent running resistance was calculated for each test.

To reproduce this experiment by numerical simulation, the authors considered a two-dimensional half-car section model, as illustrated in Fig. 4, and also a single car model including the other side of the vehicle. In this model, the contact force between wheels and sleepers was calculated as follow: First, geometrical contact between the wheelsets and sleepers was calculated for each time step for each wheelset as shown in Fig. 5. Where contact was found between a wheelset and a sleeper the acting force between them was calculated in accordance with spring-damper model shown in Fig. 6. In this model, the mounting angle of the virtual spring-damper $(\alpha)$ was set to the contact angle between the wheelset and the sleeper and was variable with time. Numerical simulations were then conducted corresponding to the running tests of the model vehicle using the two-dimensional single car section model, and the equivalent running resistance was calculated similar to the manner described above.

The results of the equivalent running resistance derived from running tests and calculation results were superposed and are given in Fig. 7. Figure 7 shows that the tendencies in variation of running resistance of the vehicle against vehicle speed are similar to each other for both types of sleepers, and differ from the running resistance generally associated to the wheelset when it is on rails. The value of the running resistance grew as vehicle speed increased from $0 \mathrm{~km} / \mathrm{h}$ to about $20 \mathrm{~km} / \mathrm{h}$, then decreased when the vehicle speed exceeded $20 \mathrm{~km} / \mathrm{h}$ to about $60 \mathrm{~km} / \mathrm{h}$ because the wheels began jumping over sleepers preventing any decelerating force from acting on the wheel. However, the resistance began to rise again when the vehicle speed surpassed $60 \mathrm{~km} / \mathrm{h}$ due to increase in resistance forces other than the collision force between wheels and sleepers, such as air resistance. The value of the running resistance of a narrow sleeper was bigger than for a wide sleeper. The calculated results mostly coincided with test results for both types of sleepers, validating the developed numerical dynamics model of the model vehicle, especially the contact model of wheels and sleepers.

\section{Three-dimensional vehicle dynamics simulation which can be applied to post-derailment situa- tions}

After having validated the simulation model described in section 2.3, the authors extended the simulation model and developed a three-dimensional vehicle dynamics simulation program capable of modeling the train after derailment and when it runs on sleepers or ballast. It was mentioned under reference [1] that the lateral declination of the derailed car might be reduced if a stronger brake force was applied to cars located behind the derailed car in the train. Using the developed program, the authors constructed the five-car train numerical model and validated the effect of reducing the lateral declination of the derailed car by varying the braking force in the train.

\subsection{Modeling of a vehicle}

The vehicle in the numerical simulation program was composed of nine bodies: four wheelsets, two bogies, a car body and two couplers. Each body had seven degrees of freedom (because rotation is represented by the Euler parameters in this simulation), so overall the vehicle had 63 degrees of freedom in all. Other principal conditions for simulations are shown in Table 2. 
Table 2 Conditions for numerical simulations

\begin{tabular}{|c|l|}
\hline $\begin{array}{c}\text { Track condition } \\
\text { inclination }\end{array}$ & Straight track with no irregularity \\
\hline Car & $1435 \mathrm{~mm}, 1 / 40$ \\
\hline Wheel tread profile & Shinkansen arc tread \\
\hline Rail profile & JiS $60 \mathrm{~kg}$ \\
\hline $\begin{array}{c}\text { Werailment force of } \\
\text { wheelset set to be derailed }\end{array}$ & $\begin{array}{l}\text { Set arbitrarily } \\
\text { wheelset } 0.5 \text { second after the train starts until its lateral displacement } \\
\text { exceeds } 40 \text { mm. }\end{array}$ \\
\hline $\begin{array}{c}\text { Brake (if applied) } \\
\text { Contact calculation } \\
\text { between wheel and rail }\end{array}$ & $\begin{array}{l}\text { Brake torque corresponding to the designated deceleration is applied } \\
\text { to wheelsets } 1.5 \text { second after train starts. }\end{array}$ \\
\hline $\begin{array}{l}\text { Calculate in advance contact conditions based on contact table files in } \\
\text { the case where the lateral displacement of wheelset is in the range of } \\
\pm 70 \text { mm, then execute online evaluation after the displacement ex- } \\
\text { ceeds } \pm 70 \text { mm, considering contacts between wheels and sleepers or } \\
\text { ballast and contacts between wheel rims and side surfaces of rail }\end{array}$ \\
\hline
\end{tabular}

\subsection{Construction of contact models between wheels and sleepers, and between wheels and ballast}

First, the authors modeled concrete sleepers on type $4 \mathrm{Hk}$ and assumed that the sleeper had a uniform section in the longitudinal direction for simplicity as shown in Fig. 8. In the numerical simulation 43 sleepers were set per 25 meters. The simulation allows for the position of right and left wheels to be different in the three-dimensional simulation, unlike two-dimensional simulation explained in the section 2.3 , because of rolling and yawing of bogie in reality; so determination of geometrical contact (Fig. 5) and calculation of acting force between wheels and sleepers (Fig. 6) were made for each wheel, not for the wheelset. In order to calculate the normal force between wheels and sleepers the test results mentioned in references such as [2], etc. were used to estimate the spring and damper constant in Fig. 6, and those mentioned in reference [3] for calculating tangential force. It was assumed that the tangential force was saturated at 0.18 times the normal force.

Secondly in order to include the case of a wheel running on ballast, the authors conducted running tests where a real single bogie was dropped onto ballast (Fig. 9). Acceleration of the bogie frame and sinking of the wheels into the ballast were measured. Figure 10 shows a result of the longitudinal acceleration of the bogie frame.

It shows that there is a deceleration of approximately $3 \mathrm{~m} / \mathrm{s}^{2}$ as the wheelset falls onto the track and is running on ballast. Wheel sinkage and deceleration of the bogie frame were analyzed from test results, and outcome of this experiment, numerical simulation was performed by means of terramechanics. Referring to the modeling of con-
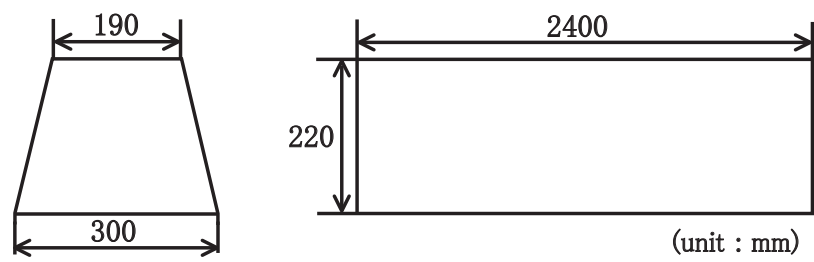

(unit : $\mathrm{mm}$ )

Fig. 8 Sleeper model

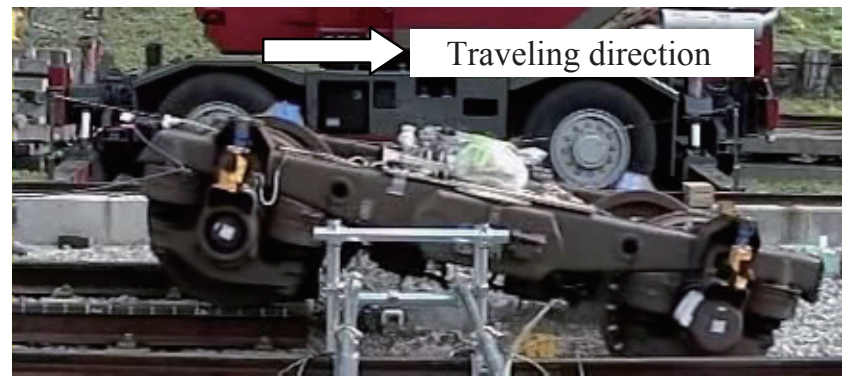

Fig. 9 Falling test of a bogie onto ballasted track

1st wheelset 2st wheelset

fall onto the track fall onto the track

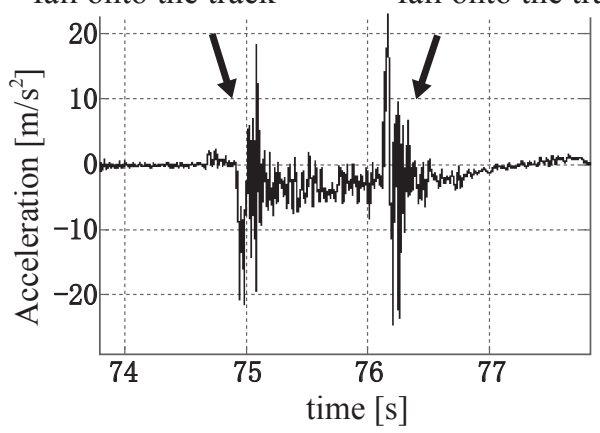

Fig. 10 Acceleration of bogie frame in falling test

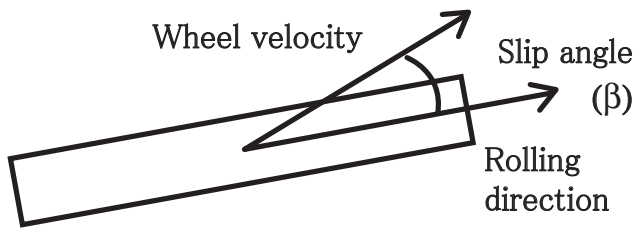

Fig. 11 Slip angle in the simulation model

tact used in reference [4] etc., it was assumed that the longitudinal, lateral, and vertical contact forces between the wheels and ballast were functions of hf: sinkage of wheel, and $\beta$ : slip angle of wheel (i.e. angle between wheel velocity and rolling direction of the wheel (Fig. 11)); these forces 


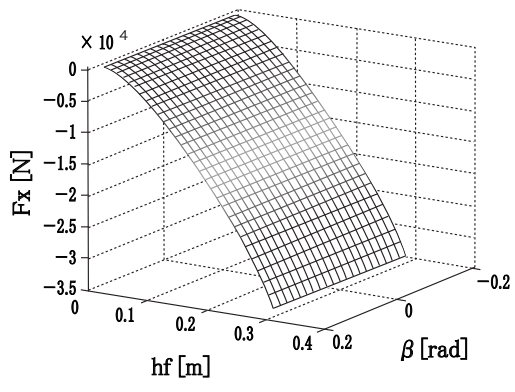

(a) Longitudinal force

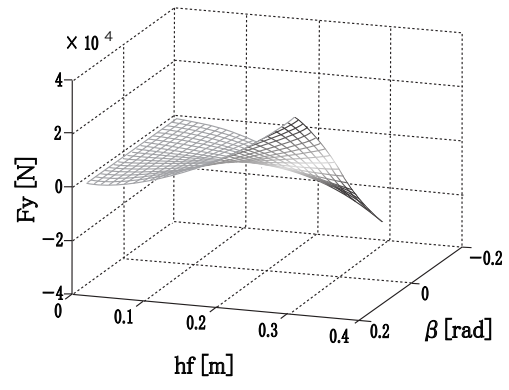

(b) Lateral force

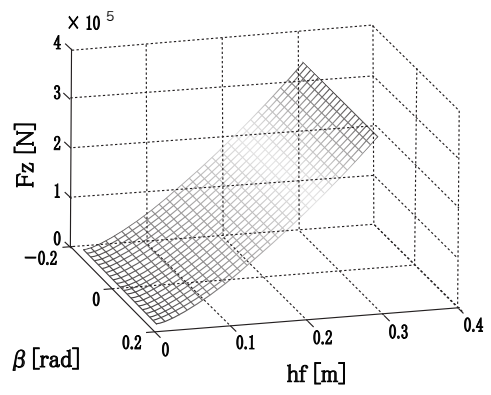

(c) Vertical force

Fig. 12 Tabulated forces applied to a wheel from ballast

were calculated in advance. The calculated forces were tabulated and are shown in Fig. 12(a) $\sim$ (c). The results of the falling test were approximated and included in the tables. The speed of the bogie frame in the test however was slow up to about $10 \mathrm{~km} / \mathrm{h}$, and the sinkage of wheels was up to about $10 \mathrm{~cm}$. This means that there are still gaps in the explanation of how contact forces can change with the increase in speed and sinkage, indicating an issue which will need to be pursued in the future.

\section{Results from simulation of a five-car train after derailment}

The authors conducted numerical experiments with the five-car train described in Chapter 3. The train speed was set to 70,160 and $275 \mathrm{~km} / \mathrm{h}$, and the derailed wheelset belonged to the first wheelset of car No.3 (Fig. 13). The brake settings and deceleration in braking are shown in Table 3 and 4. Pattern 2 in Table 3, shows that deceleration is generally set $2 \mathrm{~km} / \mathrm{h} / \mathrm{s}$ above that of pattern 1 . Cars other than those to which brake force is applied are not braked, in order to increase the difference in braking force in the train.

Figures 14 (a) (c) show the lateral displacement of the derailed first bogie of car No.3. Figure 14 (a) demonstrates that the wheelsets of the first bogie of car No.3 are pulled back to almost the center of the track, where they are running on sleepers. If train speed is higher however the lateral displacement stays smaller in pattern 2 than that pattern 1 between $1.5 \mathrm{~s}$ (the time brake force starts to be applied) and about $5 \mathrm{~s}$, whereas it becomes larger at
Table 3 Brake Setting

\begin{tabular}{|c|l|}
\hline Pattern & Amount of brake torque \\
\hline $\begin{array}{c}\text { 1. Distribute brake torque } \\
\text { equally to all wheelsets }\end{array}$ & $\begin{array}{l}\text { Brake torque correspond- } \\
\text { ing to the deceleration of } \\
\text { the pattern 1 in Table 4 }\end{array}$ \\
\hline $\begin{array}{c}\text { 2. Distribute brake torque } \\
\text { only to wheelsets be- } \\
\text { longing to car No.4 and } \\
\text { No.5 }\end{array}$ & $\begin{array}{l}\text { Brake torque correspond- } \\
\text { ing to the deceleration of } \\
\text { the pattern } 2 \text { in Table 4 }\end{array}$ \\
\hline
\end{tabular}

Table 4 Deceleration

\begin{tabular}{|l|l|l|l|}
\hline $\begin{array}{l}\text { Car velocity } \\
{[\mathrm{km} / \mathrm{h}]}\end{array}$ & $\begin{array}{l}\text { Deceleration } \\
(\text { Pattern } 1) \\
{[\mathrm{km} / \mathrm{h} / \mathrm{s}]}\end{array}$ & $\begin{array}{l}\text { Deceleration } \\
(\text { Pattern2) } \\
{[\mathrm{km} / \mathrm{h} / \mathrm{s}]}\end{array}$ & $\begin{array}{l}\text { Deceleration } \\
(\text { Pattern3) }\end{array}$ \\
\hline 70 & 3.1 & 5 & ----------------- \\
\hline 160 & 2.5 & 4.5 & Pattern2 $+10 \mathrm{kN}$ \\
\hline 275 & 1.9 & 3.9 & Pattern2 $+10 \mathrm{kN}$ \\
\hline
\end{tabular}

around $6 \sim 7 \mathrm{~s}$ (Figs. 14(b) and (c)). The braking force in pattern 3 was made to be larger than in the pattern 2 . An additional $10 \mathrm{kN}$ braking force was added to each bogie of car No.4 and 5 imitating a rail brake. The calculation results for pattern 3 are shown in Figs. 14(b) and (c).

Results with pattern 3 show that where the brake force in the rearward cars of the train is greatest lateral displacement remains smaller than in pattern 1 , at all times, when the train speed is at least $160 \mathrm{~km} / \mathrm{h}$. This raises the possibility that reducing lateral displacement of derailed cars to some extent may be achieved by applying stronger braking force to the rearward cars.

The first wheelset of Car

Wheelsets only belonging to

No.3 is set to be derailed car No.4 and No.5 are braked in the pattern 2 .

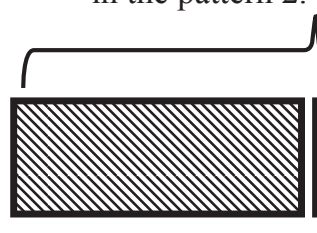

Car 5

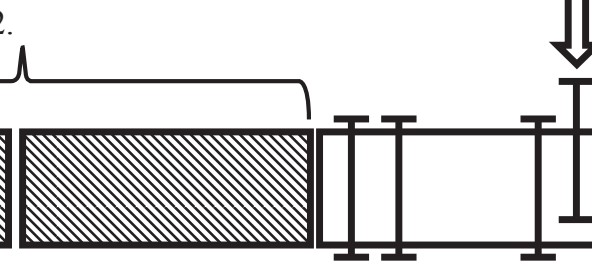

Car 3
Travelling direction

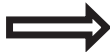

Fig. 13 Simulation conditions for derailed traint 


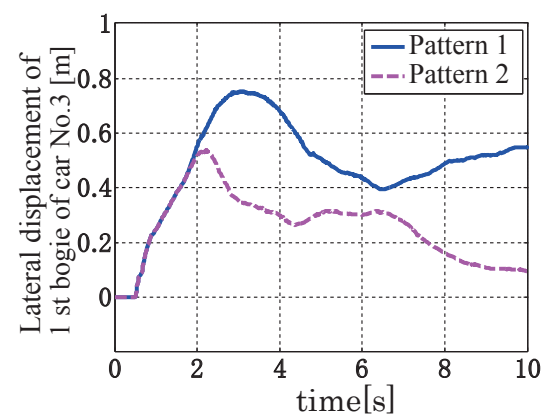

(a) Lateral displacement of derailed bogie

$(70 \mathrm{~km} / \mathrm{h})$

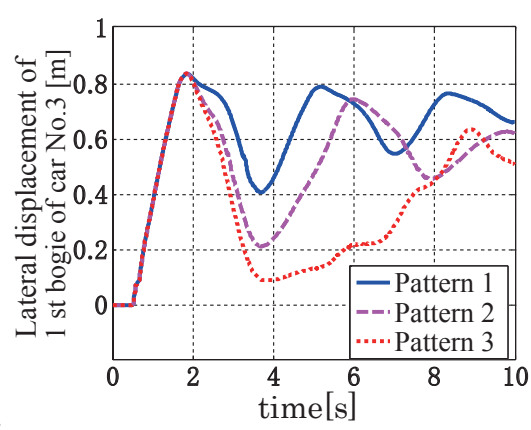

(b) Lateral displacement of derailed bogie

$(160 \mathrm{~km} / \mathrm{h})$

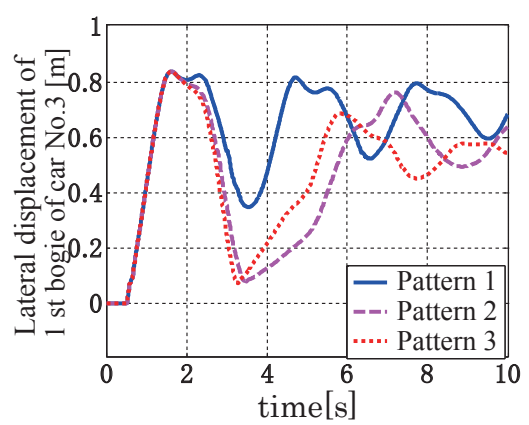

(c) Lateral displacement of derailed bogie $(275 \mathrm{~km} / \mathrm{h})$

Fig. 14 Lateral displacement of derailed bogie

\section{Conclusions}

A 1 to 10 scale model vehicle was built and used in running tests for this study. The tests involved colliding the vehicle against model iron sleepers. Further running tests were performed with a real single bogie dropping onto ballast or a concrete sleeper. Subsequently a threedimensional numerical simulation program was developed capable of calculating the dynamic motion of a train after derailment. This was applied to compute the dynamic behavior of five cars after derailment. The model vehicle running tests results demonstrated that there was a difference with the generally known running resistance of the vehicles on rails. The dynamic behavior of the five-car train after its derailment was examined while varying the brake force applied. Numerical simulation revealed that applying stronger braking forces to cars rearward to the derailed car up to around $70 \mathrm{~km} / \mathrm{h}$ was effective in reducing lateral displacement of the derailed car, though this benefit weakened as train speed increased. These investigations also lead to the suggestion that the aforementioned effectiveness can still be found even at higher speed when the larger braking forces applied do not depend on wheelrail adhesion force, but are applied through a rail brake or aerodynamic brakes, etc.

\section{Acknowledgment}

The authors would like to express our sincere gratitude to staff of the East Japan Railway Company for their indispensable work on the model vehicle running tests and collection of experimental data.

\section{References}

[1] Suzuki, F., Sasaki, K., "Influence of Derailed Wheelsets on Trainset Behavior," Proceedings of the 16th Jointed Railway Technology Symposium 2009, pp.511514, 2009(in Japanese).

[2] Gotoh, K., Sogabe, M., and Asanuma, K., "Experimental Study on Evaluation of Conact Force between a Train Wheel and a PC Sleeper," Proceedings of the Japan Concrete Institute, Vol.33, No.2, pp.781-786, 2011(in Japanese).

[3] Doi, H., Miyamoto, T., Nishio, S., Goan, S., and Ueda, H., "Experimental Investigation of Friction Coefficient Between Steel Wheel And Concrete Slab," RTRI Report, Vol.24, No.4, pp.23-26, 2010(in Japanese).

[4] Ishigami, G., Miwa, A., Nagatani, K., and Yoshida, K., "Terramechanics-Based Model for Steering Maneuver of Planetary Exploration Rovers on Loose Soil," Journal of Field Robotics, Vol.24, No.3, pp.233-250, 2007. 